\title{
Decavanadate as a biochemical tool in the elucidation of muscle contraction regulation
}

\author{
Teresa Tiago $^{\mathrm{a}, *}$, Manuel Aureliano ${ }^{\mathrm{a}}$, José J.G. Moura ${ }^{\mathrm{b}}$ \\ a Departamento de Química e Bioquímica, Faculdade de Ciências e Tecnologia, Universidade do Algarve, FCT, UALG, \\ Gambelas, 8005-139 Faro, Portugal \\ ${ }^{\mathrm{b}}$ Departamento de Química, Universidade Nova de Lisboa, 2825-114 Caparica, Portugal
}

Received 28 May 2004; received in revised form 17 August 2004; accepted 20 August 2004

Available online 23 September 2004

\begin{abstract}
Recently reported decameric vanadate $\left(\mathrm{V}_{10}\right)$ high affinity binding site in myosin $\mathrm{S} 1$, suggests that it can be used as a tool in the muscle contraction regulation. In the present article, it is shown that $\mathrm{V}_{10}$ species induces myosin $\mathrm{S} 1$ cleavage, upon irradiation, at the 23 and $74 \mathrm{kDa}$ sites, the latter being prevented by actin and the former blocked by the presence of ATP. Identical cleavage patterns were found for meta- and decavanadate solutions, indicating that $\mathrm{V}_{10}$ and tetrameric vanadate $\left(\mathrm{V}_{4}\right)$ have the same binding sites in myosin S1. Concentrations as low as $50 \mu \mathrm{M}$ decavanadate $\left(5 \mu \mathrm{M} \mathrm{V} \mathrm{V}_{10}\right.$ species) induces $30 \%$ of protein cleavage, whereas $500 \mu \mathrm{M}$ metavanadate is needed to attain the same extent of cleavage. After irradiation, $\mathrm{V}_{10}$ species is rapidly decomposed, upon protein addition, forming vanadyl $\left(\mathrm{V}^{4+}\right)$ species during the process. It was also observed by NMR line broadening experiments that, $\mathrm{V}_{10}$ competes with $\mathrm{V}_{4}$ for the myosin $\mathrm{S} 1$ binding sites, having a higher affinity. In addition, $\mathrm{V}_{4}$ interaction with myosin $\mathrm{S} 1$ is highly affected by the products release during ATP hydrolysis in the presence or absence of actin, whereas $\mathrm{V}_{10}$ appears to be affected at a much lower extent. From these results it is proposed that the binding of vanadate oligomers to myosin S1 at the phosphate loop ( $23 \mathrm{kDa}$ site) is probably the cause of the actin stimulated myosin ATPase inhibition by the prevention of ATP/ADP exchange, and that this interaction is favoured for higher vanadate anions, such as $\mathrm{V}_{10}$.
\end{abstract}

(C) 2004 Elsevier Inc. All rights reserved.

Keywords: Decavanadate; Myosin; Photocleavage; NMR

\section{Introduction}

Interest in the interaction of vanadate oxoanions with biological systems has increased gradually since it was demonstrated to have a variety of physiological effects acting either as a phosphate analogue in the monomeric form $\left(\mathrm{H}_{2} \mathrm{VO}_{4}^{-}\right)$[1] or through oligomeric vanadate species. Although it is often disregarded which of the oxovanadates is the active species, most of the studies are conducted at such low concentrations that the major species in solution is the monomer. Among the oligo-

\footnotetext{
${ }^{*}$ Corresponding author. Tel.: +96 28513 19; fax: +289 819403 .

E-mail address: ttiago@ualg.pt (T. Tiago).
}

meric species, probably the most interesting in biochemical terms is the decamer $\left(\mathrm{V}_{10} \mathrm{O}_{28}^{6-}\right)$, although it has been reported that dimeric $\left(\mathrm{H}_{3} \mathrm{~V}_{2} \mathrm{O}_{7}^{-}\right)$and cyclic tetrameric $\left(\mathrm{V}_{4} \mathrm{O}_{12}^{4-}\right)$ forms may also influence the activity of several enzymes [2,3]. Vanadate has also proved to be a valuable tool to trap $\mathrm{Mg}^{2+}$ nucleotides in the catalytic site of ATPases, particularly for mapping the active site of myosin.

Myosin is the major muscle ATPase, which along with actin converts the chemical energy of ATP hydrolysis into mechanical work [4,5]. Vanadate inhibits myosin ATPase activity through the formation, in the absence of actin, of a long-lived complex with MgADP that is believed to mimic the transition state of myosin**-ADP-Pi [6]. In the 
presence of actin, the rate of vanadate release increases by $10^{5}$ compared to that of myosin.ADP. $V_{1}$ alone $\left(5 \times 10^{-6}\right.$ $\mathrm{s}^{-1}$ ), and consequently the inhibition is reverted [7]. Nevertheless, it has been described that as long as excess Vi is present (denoting a mixture of monomeric and polymeric vanadate ions), the formation of the myosin.ADP. $V_{1}$ complex is favoured even with the "destabilizing" influence of actin $[8,9]$. Indeed, recently it was demonstrated that the decameric vanadate $\left(\mathrm{V}_{10}\right)$ inhibits the actin-stimulated myosin ATPase activity, noncompetitively with actin or with ATP upon interaction with a high-affinity binding site in myosin subfragment-1 (S1) [10]. In the work described by Tiago et al. [10], the interaction of $\mathrm{V}_{10}$ with myosin $\mathrm{S} 1$ was monitored using fluorescently labelled S1 at Cys-707 (SH1) and Cys-697 (SH2), and the results pointed out that the binding of $\mathrm{V}_{10}$ to myosin is very close to Cys-697. The flexible loop between Cys-707 and Cys-697 is believed to act as an energy transduction element through which intersite communication between ATP and actin binding sites is transmitted [11], and therefore could be related to the mechanism by which $\mathrm{V}_{10}$ (and probably other vanadate oligomers) impairs the actinstimulated myosin ATPase activity. Moreover, it was found that $\mathrm{V}_{10}$ binding is competitive with the $\gamma$-phosphate modified nucleotide analogue, $\mathrm{AP}_{5} \mathrm{~A}[10]$. The $\gamma$-phosphate of ATP lies adjacent to Ser-180 and Ser243 , two residues demonstrated to be photomodified by tetrameric vanadate $\left(\mathrm{V}_{4} \mathrm{O}_{12}^{4-}\right)$ upon UV irradiation [12]. On this basis, it was suggested that $\mathrm{V}_{10}$ binds to the phosphate loop (amino acids 178-185), that forms part of the consensus ATP binding site on myosin, affecting the actin stimulated myosin ATPase activity. However, the analysis supporting this hypothesis has not yet been reported, as the residues implicated in $\mathrm{V}_{10}$ interaction with myosin were not clearly identified. Moreover, it is still unknown whether the other vanadate oligomers, particularly the tetrameric vanadate, inhibit the actin stimulated myosin ATPase activity through the same mechanism as $\mathrm{V}_{10}$. Thus, in the present study, we further explore the mode of action of decameric vanadate $\left(\mathrm{V}_{10}\right)$ on myosin, by analysing the following aspects: (i) $\mathrm{V}_{10}$ binding sites on myosin by showing unambiguously the residues undergoing photo-cleavage due to the presence of decameric vanadate; (ii) competition between decameric vanadate and other vanadate oligomers for the binding sites on myosin under the influence of natural ligands, such as actin and/or ATP, as analysed by ${ }^{51} \mathrm{~V}$ NMR spectroscopy.

\section{Materials and methods}

\subsection{Protein preparation}

Myosin was prepared from leg and dorsal white rabbit skeletal muscle, as previously described by Pires et al. [13]. The isolated myosin was then digested with $\alpha-$ chymotrypsin to obtain subfragment-1 (S1) according to Margossian and Lowey [14]. F-actin was prepared from acetone powder of rabbit skeletal muscle by the method of Pardee and Spudich [15]. The complexes $\mathrm{S} 1 \cdot \mathrm{ADP} \cdot \mathrm{VO}_{4}^{3-}$ and $\mathrm{S} 1 \cdot \mathrm{ADP} \cdot \mathrm{AlF}_{4}^{-}$for the photocleavage experiments were prepared according to Werber et al. [16]. Briefly, S1 previously dialyzed against $60 \mathrm{mM} \mathrm{KCl}, 25 \mathrm{mM}$ Hepes (4-(2-hydroxyethyl)-1-piperazine ethane sulfonic acid), $\mathrm{pH} 7.9$ was incubated at $25^{\circ}$ $\mathrm{C}$ for 5 min with $1 \mathrm{mM} \mathrm{MgCl}, 0.2 \mathrm{mM}$ ADP and, for $\mathrm{AlF}_{4}^{-}$with $5 \mathrm{mM} \mathrm{NaF}$. Then, metavanadate solution (for $\mathrm{VO}_{4}^{3-}$ ) or $\mathrm{AlCl}_{3}$ (for $\mathrm{AlF}_{4}^{-}$) was added to a final concentration of $0.2 \mathrm{mM}$ and the incubation was continued for $90 \mathrm{~min}$ at $25^{\circ} \mathrm{C}$. Finally, the samples were passed through a PD-10 column (Pharmacia) in order to remove excess of nucleotide analogues. Myosin and Subfragment-1 concentrations were determined by the Bradford assay using bovine serum albumin as a standard, while G-actin concentration was measured spectrophotometrically by using an extinction coefficient of $e_{290}^{1 \%}=11.5 \mathrm{~cm}^{-1}$. Molecular weights of 500,115 , and $42 \mathrm{kDa}$ were considered for myosin, $\mathrm{S} 1$, and actin, respectively.

\subsection{Vanadate solutions}

Metavanadate solution (50 mM, pH 6.0-7.0) was prepared from ammonium metavanadate $\left(\mathrm{NH}_{4} \mathrm{VO}_{3}\right)$ purchased from Riedel-de-Haen. Decavanadate solution was prepared in a manner that maximized the proportion of vanadate that was present as the decamer, by adjusting the $\mathrm{pH}$ of the metavanadate solution to 4.0 [17]. The presence of decameric vanadate species was revealed by a characteristic orange colour. Both solutions were kept at $4{ }^{\circ} \mathrm{C}$.

\subsection{Photocleavage studies}

Photoirradiation was carried out in a reaction mixture containing $4.5 \mu \mathrm{M}$ myosin $\mathrm{S} 1,25 \mathrm{mM} \mathrm{KCl}, 2.5$ $\mathrm{mM} \mathrm{MgCl} 2,25 \mathrm{mM}$ Hepes, $\mathrm{pH} 7.0$, in the presence or absence of $5-1000 \mu \mathrm{M}$ vanadate solutions, $5 \mathrm{mM}$ ATP and $10 \mu \mathrm{M}$ actin. The mixture $(2 \mathrm{ml})$ in quartz cell and cooled on a water bath was irradiated with a 400 W medium-pressure $\mathrm{Hg}$ lamp (Applied Photophysics) at an average distance of $5 \mathrm{~cm}$. Radiation below 300 $\mathrm{nm}$ was removed (in order to prevent protein degradation by UV irradiation) by using a $\mathrm{CuSO}_{4}$ solution, having a peak of transmittance at $365 \mathrm{~nm}$. The sample was then subjected to electrophoretic analysis on a $12 \%$ sodium dodecyl sulfate (SDS)-polyacrylamide gel.

\subsection{NMR measurements}

1D ${ }^{51} \mathrm{~V}$ NMR spectroscopy measurements were performed on a Bruker AM- $400 \mathrm{MHz}$ spectrometer at 
105.2 $\mathrm{MHz}$ equipped with a $5 \mathrm{~mm}$ multinuclear inverse probe. Spectra were acquired at $22{ }^{\circ} \mathrm{C}$ using $0.5 \mathrm{ml}$ of samples containing $10 \% \mathrm{D}_{2} \mathrm{O}$, under the following conditions: $90^{\circ}$ pulse angle, spectral width $23923 \mathrm{~Hz}$, acquisition time $0.086 \mathrm{~s}$, number of transients 10000 and relaxation delay $0.01 \mathrm{~s} .{ }^{51} \mathrm{~V}$ NMR chemical shifts are reported relative to an external reference of $\mathrm{VOCl}_{3}(0$ ppm). NMR spectra of metavanadate $(2 \mathrm{mM})$ and polyvanadate ( $2 \mathrm{mM}$ metavanadate $+5 \mathrm{mM}$ decavanadate) solutions were obtained in a reaction medium containing $25 \mathrm{mM} \mathrm{KCl}, 2.5 \mathrm{mM} \mathrm{MgCl}_{2}, 25 \mathrm{mM}$ Hepes, $\mathrm{pH}$ 7.0 in the absence and presence of myosin S1, actin or ATP as desired. The ${ }^{51} \mathrm{~V}$ NMR line widths of the several free and bound vanadate resonances represent the widths at half-height after subtraction of $20 \mathrm{~Hz}$ used in line broadening. The concentrations of each vanadate species $\mathrm{V}_{x}$ were calculated from the fractions of the total integrated areas using the following equation: $\left[\mathrm{V}_{x}\right]=\left(A_{x} / A_{\mathrm{t}}\right) \times\left(\left[\mathrm{V}_{\mathrm{t}}\right] / n\right)$, where $A_{x}$ corresponds to the area measured for the $x$ vanadate species with $n$ aggregation number (number of vanadium atoms), $A_{\mathrm{t}}$ the sum of measured areas, and $\left[\mathrm{V}_{\mathrm{t}}\right]$ the total vanadate concentration, as described elsewhere [17].

\section{Results and discussion}

Vanadate is photochemically active and irradiation of protein-bound vanadate species with UV light results in polypeptide photo-oxidation and cleavage making possible the identification of vanadate binding sites [18-21]. In the present work, a series of decavanadatedependent photocleavage experiments were carried out in order to clearly identify decameric vanadate $\left(\mathrm{V}_{10}\right)$ binding sites on myosin. The electrophoretic patterns were analyzed and the results are summarized in Fig. 1. It was observed that irradiation of myosin S1 $(4.5 \mu \mathrm{M})$ for $20 \mathrm{~min}$, in the presence of $100 \mu \mathrm{M}$ decavanadate $\left(10 \mu \mathrm{M} \mathrm{V} V_{10}\right.$ species $)$, caused the cleavage of the S1 $95 \mathrm{kDa}$ heavy chain at the $23 \mathrm{kDa}$ - and, to a much lower extent, at the $74 \mathrm{kDa}$-sites, producing the 23 and $21 \mathrm{kDa}$ cleavage products, respectively (Fig. 1(A), lane b). An additional product of $51 \mathrm{kDa}$ also appears, likely derived from the further cleavage of the 74 $\mathrm{kDa}$ fragment. In presence of $2 \mathrm{mM}$ ATP, the cleavage at the $23 \mathrm{kDa}$ is inhibited leaving only the $74 \mathrm{kDa}$ site available to photocleavage as can be seen from the appearance of a tenuous $21 \mathrm{kDa}$ band (Fig. 1(A), lane c). The same observation was verified in the presence of S1-ADP-V $V_{1}$ and S1-ADP-AlF 4 (Fig. 1(A), lanes $g$ and $\mathrm{i}$, respectively), two complexes known to mimic the intermediate activated myosin**-ADP-Pi state $[16,22,23]$. In presence of actin $(10 \mu \mathrm{M})$, the cleavage at the $74 \mathrm{kDa}$ site was totally protected while enhancing the cleavage at the $23 \mathrm{kDa}$ site (Fig. 1(A), lane d). However, when ATP is added in the presence of actin, the 23
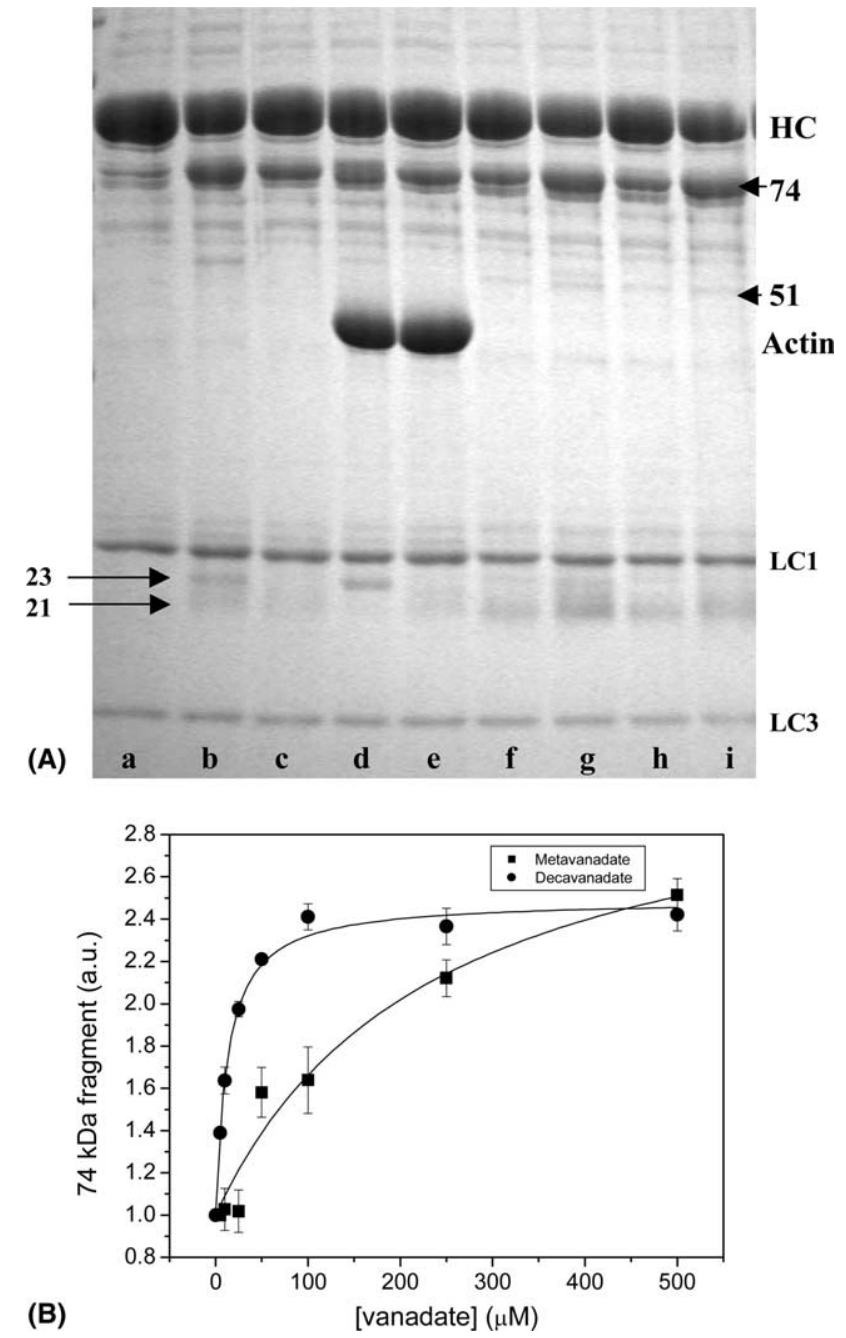

Fig. 1. SDS-PAGE analysis of the Vi-dependent photocleavage of myosin $\mathrm{S} 1(4.5 \mu \mathrm{M})$ in a medium containing $25 \mathrm{mM} \mathrm{KCl}, 2.5 \mathrm{mM}$ $\mathrm{MgCl}_{2}, 25 \mathrm{mM}$ Hepes, $\mathrm{pH}$ 7.0. Samples were irradiated for $20 \mathrm{~min}$. as stated in Materials and Methods section and then run on a $12 \%$ acrylamide gel. (Panel A) SDS gel electrophoresis pattern of S1 following irradiation in the absence (a) and presence of $10 \mu \mathrm{M} \mathrm{V}_{10}(100$ $\mu \mathrm{M}$ total vanadium added as decavanadate) with no additions (b); or with $5 \mathrm{mM}$ ATP (c); $10 \mu \mathrm{M}$ F-actin (d); and $5 \mathrm{mM} \mathrm{ATP}+10 \mu \mathrm{M} \mathrm{F}$ actin (e). Control S1-ADP- $\mathrm{V}_{1}$ in the absence (f) and presence of 10 $\mu \mathrm{M} \mathrm{V}_{10}(\mathrm{~g})$. Control S1-ADP-AlF $\mathrm{A}_{4}$ in the absence $(\mathrm{h})$ and presence of $10 \mu \mathrm{M} \mathrm{V}_{10}$ (i). (Panel B) Formation of the $74 \mathrm{kDa}$ fragment estimated from the densitometry of the peptide bands upon increasing vanadate concentration up to $500 \mu \mathrm{M}$ for metavanadate (squares) and decavanadate (circles) solutions. HC, LC1 and LC3 stands for S1 heavy chain, myosin light chain 1 and myosin light chain 3 , respectively.

$\mathrm{kDa}$ site is no longer susceptible to photocleavage by decavanadate (Fig. 1(A), lane e).

The electrophoretic patterns found for the decavanadate-dependent myosin S1 photocleavage in the present work are identical to the ones previously reported in the presence of metavanadate concentrations higher than $0.2 \mathrm{mM}$. Myosin S1 was shown to be photoirradiated by near UV-light in the presence of vanadate at three 
specific sites: 23,31 , and $74 \mathrm{kDa}$ from the $\mathrm{N}$-terminus [24]. The cleavages at the 23 and $31 \mathrm{kDa}$ sites, which were assigned to Ser-180 and Ser-243, respectively, are located in the consensus ATP binding site $[25,26]$ while the $74 \mathrm{kDa}$ site is near the Lys-rich $50 / 20 \mathrm{kDa}$ junction which is believed to participate in an actin binding site [27]. Since ${ }^{51}$ V NMR studies have shown that the tetrameric vanadate binds most strongly to myosin [12] and is favoured for vanadate concentrations higher than $0.2 \mathrm{mM}$, it was suggested that this species is the most likely responsible for the cleavage products.

Given the rapid exchange rates between the labile oligovanadates $\left(\mathrm{V}_{1}, \mathrm{~V}_{2}\right.$, and $\left.\mathrm{V}_{4}\right)$ [2] it is not possible to isolate a specific anion and consequently an equilibrium mixture must be examined, which may complicate studies aimed to determine the effect of a specific anion. Although vanadate decamer is a less labile oligomer, remaining relatively intact for studies of limited duration, in previous NMR studies it was shown that upon dilution to the reaction medium ( $\mathrm{pH} 7.0$ ), the decavanadate solution can contain approximately $10 \%$ of monomeric vanadate [17]. To ascertain whether the monomeric vanadate $\left(\mathrm{V}_{1}\right)$ added with decavanadate solutions, or eventually formed during irradiation due to decameric species decomposition, can account for the electrophoretic patterns observed in Fig. 1(A), we have carried out photocleavage reactions with $4.5 \mu \mathrm{M}$ $\mathrm{S} 1$ over a wide range of meta- and deca-vanadate con- centrations (5-1000 $\mu \mathrm{M}$ total vanadium). The formation of the $74 \mathrm{kDa}$ fragment, as estimated from the densitometry of this peptide band, was followed and the results represented in Fig. 1(B). For decavanadate, cleavage starts to occur at vanadate concentrations as low as 5 $\mu \mathrm{M}\left(0.5 \mu \mathrm{M} \mathrm{V} \mathrm{V}_{10}\right.$ species$)$ increasing sharply up to 50 $\mu \mathrm{M}$ total vanadium (5 $\mu \mathrm{M} \mathrm{V} \mathrm{V}_{10}$ species) and reaching $30 \%$ of protein cleavage. For metavanadate, cleavage at concentrations lower than $100 \mu \mathrm{M}$ (containing mainly monomeric species) is modest and, only at concentrations favouring di- and tetra-meric vanadate species $(500 \mu \mathrm{M})$, the extent of cleavage is comparable to the maximum decavanadate cleavage, ruling out the contribution of the monomeric vanadate to protein cleavage and indicating the vanadate oligomers as the photoactive species. However, for higher vanadate concentrations $(1 \mathrm{mM})$, it was observed that while for decavanadate the extent of cleavage remains essentially constant never exceeding $30 \%$, for metavanadate it exceeds $45 \%$ (results not shown).

The lower extent of cleavage found for decavanadate when compared to metavanadate solutions, at higher vanadate concentrations ( $1 \mathrm{mM})$, prompted us to monitor, by UV/VIS spectroscopy, the spectral changes in the $240-700 \mathrm{~nm}$ region of decavanadate solutions before and after exposure to irradiation, in order to examine the consequence of irradiation on $\mathrm{V}_{10}$ species stability. The results are presented in Fig. 2, as the difference
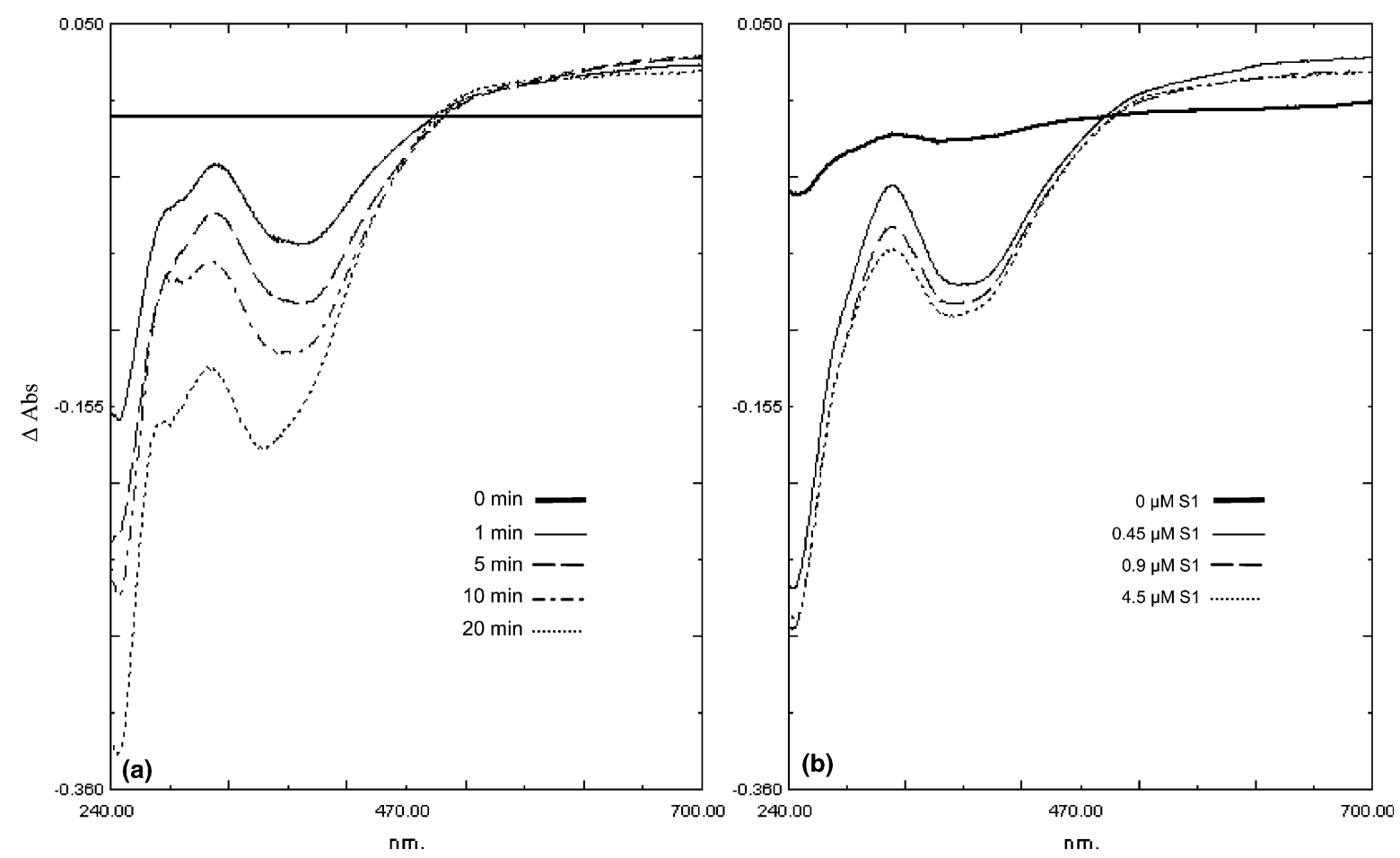

Fig. 2. UV-Vis differential spectra from $240-700 \mathrm{~nm}$ of $250 \mu \mathrm{M}$ decavanadate solution in a medium containing $25 \mathrm{mM} \mathrm{KCl}, 2.5 \mathrm{mM} \mathrm{MgCl} 2,25 \mathrm{mM}$ Hepes, pH 7.0: (a) after different times of irradiation (0-20 min) in presence of $4.5 \mu \mathrm{M}$ myosin $\mathrm{S} 1$; (b) in the presence of different myosin $\mathrm{S} 1$ concentrations $(0,0.45,0.9$ and $4.5 \mu \mathrm{M})$ at a fixed time of irradiation $(20 \mathrm{~min})$. 
between spectra after and before irradiation, showing a decrease of an absorption band centred at $390 \mathrm{~nm}$ (characteristic of decameric vanadate), corresponding to a decrease of the decamer concentration. In the presence of $4.5 \mu \mathrm{M} \mathrm{S} 1$, after $1 \mathrm{~min}$ irradiation, the absorption band at $390 \mathrm{~nm}$ of the decavanadate solution $(250 \mu \mathrm{M})$ decreases almost $38 \%$, and it reaches $80 \%$ after $20 \mathrm{~min}$, with the concomitant increase of a broad band near $700 \mathrm{~nm}$, indicative of vanadyl $\left(\mathrm{V}^{4+}\right.$ species) formation during the process (Fig. 2(a)). Furthermore, the decrease of the decameric absorption band occurs only in the presence of myosin S1, with slight changes for S1 concentrations between 0.45 and $4.5 \mu \mathrm{M}$, pointing out that $\mathrm{V}_{10}$ decomposition is promoted upon protein irradiation (Fig. 2(b)). In fact, it is known that the mechanism of vanadate-promoted photocleavage reaction on myosin involves addition of molecular oxygen to a stabilized seryl radical generated by a light-catalyzed vanadate $\left(\mathrm{V}^{5+}\right)$ reduction to vanadyl $\left(\mathrm{V}^{4+}\right)$ [28]. It was also recently shown that $\mathrm{V}^{5+}$ of $\mathrm{V}_{10}$ is more easily reduced in comparison to $\mathrm{V}_{1}, \mathrm{~V}_{2}$ and $\mathrm{V}_{4}$ present in metavanadate solutions [29]. These observations could account for the rapid decomposition of the decameric vanadate $\left(\mathrm{V}_{10}\right)$, upon protein addition, into vandyl species after a short irradiation time as described above (Fig. 2), as well as for the higher cleavage efficiency of decavanadate for extremely low vanadate concentrations when compared to metavanadate (Fig. 1(B)).

Collectively, the results in Figs. 1 and 2 demonstrate that, besides tetrameric vanadate $\left(\mathrm{V}_{4}\right)$, also decameric vanadate $\left(\mathrm{V}_{10}\right)$ is photoactive and apparently is a better substrate for the myosin S1 photocleavage reaction than the former species. In addition, the identical cleavage patterns found for deca- and meta-vanadate solutions suggests that $\mathrm{V}_{10}$ and $\mathrm{V}_{4}$ have the same binding sites in myosin S1. On this basis, we further evaluated the
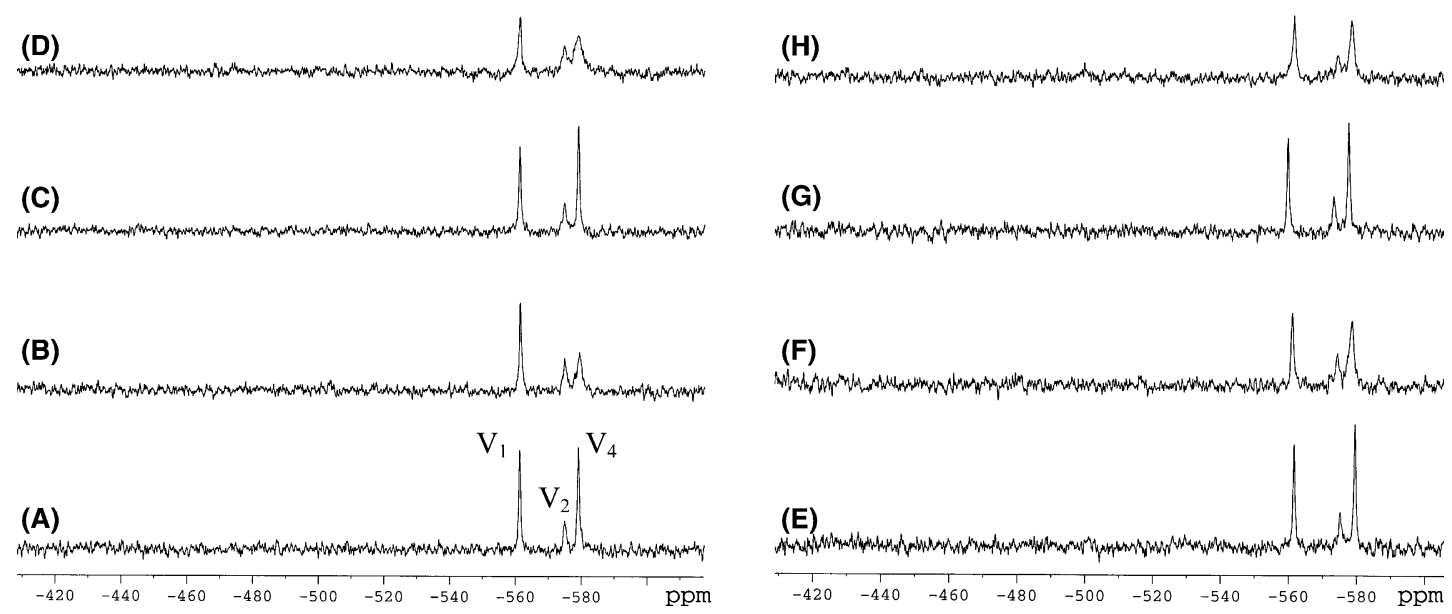

Fig. 3. ${ }^{51} \mathrm{~V}$ NMR spectra of $2.0 \mathrm{mM}$ nominal metavanadate solution in the absence (A,E) and presence of $30 \mu \mathrm{M} \mathrm{S} 1$ (B,F); $30 \mu \mathrm{M} \mathrm{F-actin} \mathrm{(C,G);} 30$ $\mu \mathrm{M} \mathrm{S} 1+30 \mu \mathrm{M}$ F-actin $(\mathrm{D}, \mathrm{H})$ with (Right panel) or without (Left panel) $2 \mathrm{mM}$ ATP. The spectra were collected in a medium containing $25 \mathrm{mM}$ $\mathrm{KCl}, 2.5 \mathrm{mM} \mathrm{MgCl}, 25 \mathrm{mM}$ Hepes, $\mathrm{pH} 7.0$ at $22{ }^{\circ} \mathrm{C} . \mathrm{V}_{1}, \mathrm{~V}_{2}$ and $\mathrm{V}_{4}$ are referring to monomeric, dimeric and cyclic tetrameric forms of vanadate, respectively. 

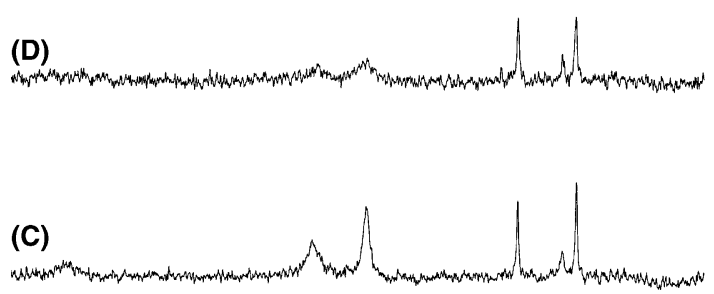

(G)

(H)

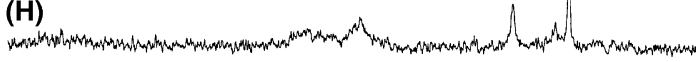
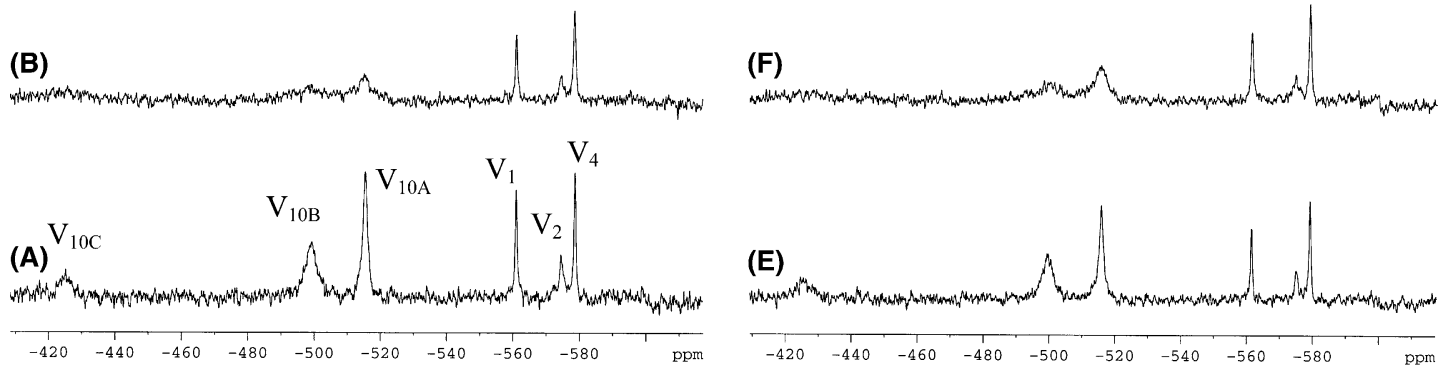

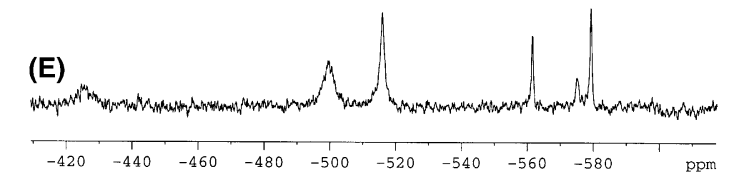

Fig. 4. ${ }^{51} \mathrm{~V}$ NMR spectra of $2.0 \mathrm{mM}$ nominal metavanadate $+5.0 \mathrm{mM}$ nominal decavanadate solutions in the absence (A,E) and presence of $30 \mu \mathrm{M}$ $\mathrm{S} 1$ (B,F); $30 \mu \mathrm{M}$ F-actin $(\mathrm{C}, \mathrm{G}) ; 30 \mu \mathrm{M} \mathrm{S} 1+30 \mu \mathrm{M}$ F-actin $(\mathrm{D}, \mathrm{H})$ with (Right panel) or without (Left panel) 2 mM ATP. The spectra were collected in a medium containing $25 \mathrm{mM} \mathrm{KCl}, 2.5 \mathrm{mM} \mathrm{MgCl}, 25 \mathrm{mM}$ Hepes, $\mathrm{pH} 7.0$ at $22{ }^{\circ} \mathrm{C}$. $\mathrm{V}_{1}, \mathrm{~V}_{2}$ and $\mathrm{V}_{4}$ are referring to monomeric, dimeric and cyclic tetrameric forms of vanadate, respectively. $\mathrm{V}_{10 \mathrm{~A}}, \mathrm{~V}_{10 \mathrm{~B}}$, and $\mathrm{V}_{10 \mathrm{C}}$ correspond to the three chemical environmental different vanadate atoms in the decameric vanadate structure.

Table 1

Chemical shifts $(\delta)$, line widths $\left(\Delta v_{1 / 2}\right)$, and broadening factor of the line widths $(\mathrm{F})$ of monomeric $\left(\mathrm{V}_{1}\right)$, dimeric $\left(\mathrm{V}_{2}\right)$, and tetrameric $\left(\mathrm{V}_{4}\right)$ forms of vanadate present in $2 \mathrm{mM}$ nominal metavanadate (META) solution in different experimental conditions

\begin{tabular}{|c|c|c|c|}
\hline & \multicolumn{3}{|c|}{ Meta $(2 \mathrm{mM})$} \\
\hline & $\mathrm{V}_{1}$ & $\mathrm{~V}_{2}$ & $\mathrm{~V}_{4}$ \\
\hline \multicolumn{4}{|l|}{ No protein $(\mathrm{A})$} \\
\hline$\delta(\mathrm{ppm})$ & -561.0 & -574.6 & -578.8 \\
\hline$\Delta v_{1 / 2}(\mathrm{~Hz})$ & 75.2 & 150.3 & 75.2 \\
\hline \multicolumn{4}{|l|}{$30 \mu \mathrm{M}$ S1 (B) } \\
\hline$\delta(\mathrm{ppm})$ & -561.2 & -574.6 & -579.1 \\
\hline$\Delta v_{1 / 2}(\mathrm{~Hz})$ & 75.2 & 150.3 & 225.6 \\
\hline$F$ (relative to A) & $(1.0)$ & $(1.0)$ & $(3.0)$ \\
\hline \multicolumn{4}{|c|}{$30 \mu \mathrm{M}$ F-actin $(\mathrm{C})$} \\
\hline$\delta(\mathrm{ppm})$ & -561.0 & -574.5 & -578.8 \\
\hline$\Delta v_{1 / 2}(\mathrm{~Hz})$ & 75.2 & 150.3 & 75.2 \\
\hline$F$ (relative to A) & $(1.0)$ & $(1.0)$ & $(1.0)$ \\
\hline \multicolumn{4}{|c|}{$30 \mu \mathrm{M} \mathrm{S} 1+30 \mu \mathrm{M}$ F-actin (D) } \\
\hline$\delta(\mathrm{ppm})$ & -561.1 & -574.6 & -578.8 \\
\hline$\Delta v_{1 / 2}(\mathrm{~Hz})$ & 112.8 & 225.6 & 376 \\
\hline$F$ (relative to C) & $(1.5)$ & $(1.5)$ & $(5.0)$ \\
\hline \multicolumn{4}{|c|}{ No protein +2 mM ATP $(\mathrm{E})$} \\
\hline$\delta(\mathrm{ppm})$ & -561.0 & -574.5 & -578.9 \\
\hline$\Delta v_{1 / 2}(\mathrm{~Hz})$ & 75.2 & 150.3 & 75.2 \\
\hline$F$ (relative to A) & $(1.0)$ & $(1.0)$ & $(1.0)$ \\
\hline \multicolumn{4}{|c|}{$3 \mu \mathrm{M} \mathrm{S} 1+2 \mathrm{mM}$ ATP $(\mathrm{F})$} \\
\hline$\delta(\mathrm{ppm})$ & -561.6 & -574.8 & -579.0 \\
\hline$\Delta v_{1 / 2}(\mathrm{~Hz})$ & 90.2 & 150.3 & 150.3 \\
\hline$F$ (relative to E) & $(1.2)$ & $(1.0)$ & $(2.0)$ \\
\hline \multicolumn{4}{|c|}{$30 \mu \mathrm{M}$ F-actin +2 mM ATP $(\mathrm{G})$} \\
\hline$\delta(\mathrm{ppm})$ & -561.0 & -574.5 & -578.9 \\
\hline$\Delta v_{1 / 2}(\mathrm{~Hz})$ & 75.2 & 150.3 & 75.2 \\
\hline$F$ (relative to E) & $(1.0)$ & $(1.0)$ & $(1.0)$ \\
\hline \multicolumn{4}{|c|}{$30 \mu \mathrm{M} \mathrm{S} 1+30 \mu \mathrm{M}$ F-actin $+2 \mathrm{mM}$ ATP $(\mathrm{H})$} \\
\hline$\delta(\mathrm{ppm})$ & -562.0 & -574.8 & -578.8 \\
\hline$\Delta v_{1 / 2}(\mathrm{~Hz})$ & 112.8 & 150.3 & 188.0 \\
\hline$F$ (relative to G) & $(1.5)$ & $(1.0)$ & $(2.5)$ \\
\hline
\end{tabular}


mately $908 \mu \mathrm{M}$ for monovanadate $\left(\mathrm{V}_{1}\right), 300 \mu \mathrm{M}$ for divanadate $\left(\mathrm{V}_{2}\right), 219 \mu \mathrm{M}$ for tetravanadate $\left(\mathrm{V}_{4}\right)$ and $461 \mu \mathrm{M}$ for decavanadate $\left(\mathrm{V}_{10}\right) .{ }^{51} \mathrm{~V}$ NMR spectra of meta- and poly-vanadate solutions were collected in the presence or absence of myosin natural ligands such as ATP and actin, and the relative order of vanadate signals line broadening upon protein addition (reflecting the interaction of vanadate species with myosin S1) was evaluated and presented in Tables 1 and 2 for metavanadate and polyvanadate solutions, respectively. The corresponding NMR spectra can be followed in Figs. 3 and 4 . Myosin S1 $(30 \mu \mathrm{M})$, selectively broadened by a factor of five and decreased the intensity of $\mathrm{V}_{4}$ resonance in the metavanadate solution with no effects on the mono- or di-vanadate signals (Table 1, Fig. 3(A)). In the same way, $V_{10}$ resonance in the polyvanadate solution was selectively broadened, by a factor of three, preventing any changes of the $\mathrm{V}_{4}$ or the other vanadate NMR signals (Table 2, Fig. 4(B)). These results implied a preferential binding of higher vanadate oligomers to the protein and suggest either a competition between decavanadate and tetravanadate for the same binding site(s), in concordance with the photocleavage studies described above, or a localized structural change caused by decavanadate that prevents tetravanadate binding. Addition of either F-actin $(30 \mu \mathrm{M})$ or ATP $(2 \mathrm{mM})$ to myosin S1 free meta- and polyvanadate samples does not induced significant differences in the line widths and chemical shifts of the vanadate resonances (Table 1, Fig. 3(C), (E) and Table 2, Fig. 4C, E for meta- and poly-vanadate samples, respectively), indicating that neither F-actin or ATP associate with any of the forms of vanadate present in the reaction medium, in agreement with previous reports [10,24]. Moreover, actin appears not to affect the binding of either $\mathrm{V}_{4}$ or $\mathrm{V}_{10}$ to myosin S1, as the increase in the line width broadening of the NMR signals upon myosin $\mathrm{S} 1$ addition is similar in the absence or presence of actin (Table 1, Fig. 3(D) and Table 2, Fig. 4(D) for $\mathrm{V}_{4}$ and $\mathrm{V}_{10}$, respectively). On the other hand, when ATP is added to the medium containing myosin S1 either in the absence (Fig. 3(F)) or presence (Fig. $3(\mathrm{H})$ ) of actin, $\mathrm{V}_{4}$ signal becomes narrow (broadening factor of 2) (Table 1) as shown previously by Ringel et al. [24] for myosin S1, in the

Table 2

Chemical shifts $(\delta)$, line widths $\left(\Delta v_{1 / 2}\right)$, and broadening factor of the line widths $(F)$ of monomeric $\left(\mathrm{V}_{1}\right)$, dimeric $\left(\mathrm{V}_{2}\right)$, tetrameric $\left(\mathrm{V}_{4}\right)$, and decameric $\left(\mathrm{V}_{10}\right)$ forms of vanadate present in $2 \mathrm{mM}$ nominal metavanadate (META) $+5 \mathrm{mM}$ nominal decavanadate (DECA) solutions in different experimental conditions

\begin{tabular}{|c|c|c|c|c|}
\hline & \multicolumn{4}{|c|}{ Meta $(2 \mathrm{mM})+$ Deca $(5 \mathrm{mM})$} \\
\hline & $\mathrm{V}_{1}$ & $\mathrm{~V}_{2}$ & $\mathrm{~V}_{4}$ & $\mathrm{~V}_{10}$ \\
\hline \multicolumn{5}{|l|}{ No protein $(\mathrm{A})$} \\
\hline$\delta(\mathrm{ppm})$ & -561.1 & -574.5 & -578.8 & -515.5 \\
\hline$\Delta v_{1 / 2}(\mathrm{~Hz})$ & 75.2 & 150.3 & 75.2 & 150.3 \\
\hline \multicolumn{5}{|l|}{$30 \mu \mathrm{M}$ S1 (B) } \\
\hline$\delta(\mathrm{ppm})$ & -561.2 & -574.7 & -578.7 & -515.2 \\
\hline$\Delta v_{1 / 2}(\mathrm{~Hz})$ & 75.2 & 188.0 & 75.2 & 450.9 \\
\hline$F$ (relative to $\mathrm{A})$ & $(1.0)$ & $(1.2)$ & $(1.0)$ & $(3.0)$ \\
\hline \multicolumn{5}{|c|}{$30 \mu \mathrm{M}$ F-actin $(\mathrm{C})$} \\
\hline$\delta(\mathrm{ppm})$ & -561.1 & -574.5 & -578.8 & -515.4 \\
\hline$\Delta v_{1 / 2}(\mathrm{~Hz})$ & 75.2 & 150.3 & 75.2 & 225.6 \\
\hline$F$ (relative to A) & $(1.0)$ & $(1.0)$ & $(1.0)$ & $(1.5)$ \\
\hline \multicolumn{5}{|c|}{$30 \mu \mathrm{M} \mathrm{S} 1+30 \mu \mathrm{M}$ F-actin (D) } \\
\hline$\delta(\mathrm{ppm})$ & -561.3 & -574.6 & -578.7 & -515.7 \\
\hline$\Delta v_{1 / 2}(\mathrm{~Hz})$ & 75.2 & 112.8 & 75.2 & 676.4 \\
\hline$F$ (relative to $\mathrm{C}$ ) & $(1.0)$ & $(1.0)$ & $(1.0)$ & $(3.0)$ \\
\hline \multicolumn{5}{|c|}{ No protein +2 mM ATP $(\mathrm{E})$} \\
\hline$\delta(\mathrm{ppm})$ & -561.1 & -574.6 & -578.8 & -515.5 \\
\hline$\Delta v_{1 / 2}(\mathrm{~Hz})$ & 75.2 & 112.8 & 75.2 & 150.3 \\
\hline$F($ relative to $\mathrm{A})$ & $(1.0)$ & $(0.8)$ & $(1.0)$ & $(1.0)$ \\
\hline \multicolumn{5}{|c|}{$30 \mu \mathrm{M} \mathrm{S} 1+2 \mathrm{mM}$ ATP $(\mathrm{F})$} \\
\hline$\delta(\mathrm{ppm})$ & -561.3 & -574.6 & -579.0 & -515.6 \\
\hline$\Delta v_{1 / 2}(\mathrm{~Hz})$ & 75.2 & 188.0 & 75.2 & 451.2 \\
\hline$F($ relative to $\mathrm{E})$ & $(1.3)$ & $(1.3)$ & $(1.0)$ & $(3.0)$ \\
\hline \multicolumn{5}{|c|}{$30 \mu \mathrm{M}$ F-actin +2 mM ATP $(\mathrm{G})$} \\
\hline$\delta(\mathrm{ppm})$ & -561.1 & -574.6 & -578.8 & -515.4 \\
\hline$\Delta v_{1 / 2}(\mathrm{~Hz})$ & 75.2 & 150.3 & 75.2 & 225.6 \\
\hline$F$ (relative to $\mathrm{E})$ & $(1.0)$ & $(1.3)$ & $(1.0)$ & $(1.5)$ \\
\hline \multicolumn{5}{|c|}{$30 \mu \mathrm{M} \mathrm{S} 1+30 \mu \mathrm{M}$ F-actin $+2 \mathrm{mM}$ ATP $(\mathrm{H})$} \\
\hline$\delta(\mathrm{ppm})$ & -561.8 & -574.7 & -578.8 & -515.4 \\
\hline$\Delta v_{1 / 2}(\mathrm{~Hz})$ & 150.3 & 150.3 & 75.2 & 451.2 \\
\hline$F$ (relative to $\mathrm{G})$ & $(1.0)$ & $(1.0)$ & $(1.0)$ & $(2.0)$ \\
\hline
\end{tabular}


absence of actin, or by Aureliano and Madeira [17] for the sarcoplasmic reticulum $\mathrm{Ca}^{2+}$-ATPase, which suggests that tetravanadate is displaced from the protein in presence of ATP either with or without actin. Contrarily to these observations, the presence of the substrate upon protein addition seems not to significantly affect the line width of $\mathrm{V}_{10}$ NMR signal in the absence, or to much lower extent in the presence of actin as can be seen from Fig. 4(F) and (H), respectively, and Table 2. When interpreting this finding we can not exclude, however, the fact that the line broadening of bound $V_{10}$ is very large and may be masking possible ATP effects on $V_{10}$ binding to myosin S1. In this regard, it may be that some displacement of decavanadate occurs although in less extent than tetravanadate. Moreover, it is known that the rapid exchange between bound and free decavanadate is likely to contribute to the disappearance of the signal even in the presence of excess vanadate [2].

In the present article, we have determined unambiguously the residues undergoing photocleavage on myosin by the decameric vanadate $\left(\mathrm{V}_{10}\right)$, demonstrating two putative binding sites: (i) one of higher affinity (23 $\mathrm{kDa}$ ) located on the 178-185 sequence (loop-P) which forms the consensus ATP binding site of myosin; and (ii) another one of lower affinity $(74 \mathrm{kDa})$ from residues 627-646 (loop-2), which is part of the actin-binding interface. These results came to confirm the hypothesis recently proposed by Tiago et al. [10] of the preference $\mathrm{V}_{10}$ binding to the Walker A motif or P-loop on myosin which forms part of the phosphate tube. Yount et al. [9] have previously postulated that actin binding promotes the movement of P-loop, containing Ser-181, which allows Pi from ATP to leave via a "back-door" in the $50-\mathrm{kDa}$ fragment while ADP is still bound at the active site. It was also proposed by the same authors that in fibers, vanadate could enter the active site via the "back-door" to form the more stable MgADP.Vi.myosin complex inducing muscle relaxation. However, this is only possible if an excess vanadate is present which is described to favour vanadate oligomerization. In fact, it was shown that $\mathrm{V}_{10}$ binding produces non-competitive inhibition of the actin-stimulated S1-ATPase activity $\left(K_{i}=0.27 \pm 0.05 \mu \mathrm{M}\right)$, without causing dissociation of the acto-S1 complex [10]. Altogether, these results suggest that the replacement of the $\gamma$-phosphate of ATP by $\mathrm{V}_{10}$ at the phosphate loop, forming the $\mathrm{V}_{10}$-myosinADP-Mg complex during ATP hydrolysis, will probably block actin-stimulated S1-ATPase activity acting as a "back-door stop" by preventing ADP/ATP exchange.

Another important result is that $V_{10}$ and $V_{4}$ bind to the same protein binding site(s), although its interactions are differently modulated by the myosin natural ligands (ATP and actin). While $\mathrm{V}_{4}$ is highly affected by the products release during ATP hydrolysis, $\mathrm{V}_{10}$ appears to be affected at a much lower extent, as shown by the NMR line broadening experiments. In addition, $\mathrm{V}_{10}$ has a greater affinity for myosin binding sites than $V_{4}$, in the same way that, $\mathrm{V}_{4}$ has a greater affinity than the lower vanadate oligomers, which can be explained if electrostatic forces play an important role in vanadate interaction with myosin. In this sense, it is concluded that besides $\mathrm{V}_{10}$, other vanadate oligomers may contribute to the inhibition of the actin-stimulated myosin ATPase activity, through binding at the myosin phosphate loop, although the protein affinity is favoured for higher vanadate anions such as $\mathrm{V}_{10}$.

Even if $\mathrm{V}_{10}$ is not likely to be present at significant concentrations under physiological conditions, it has revealed to be a useful biochemical tool not only for the description of the location and function of the phosphate binding sites on myosin, but also for the molecular interpretation of actomyosin interactions and consequently for muscle contraction regulation.

\section{Acknowledgements}

This work was supported by the Ph.D. Grant SFRH/ BD/2924/2000 from Portuguese Foundation for Science and Technology (FCT) and by the POCTI program financed through FEDER for the research project 38191/QUI/2001.

The authors gratefully acknowledge Professor C.M.D. Mateus (FCT, UALG) for providing the facilities for the photocleavage experiments and Dr. Maria do Rosário Caras Altas for the excellent technical assistance provided at the Laboratório de Ressonância Magnética Nuclear, Departamento de Química, Universidade Nova de Lisboa.

\section{References}

[1] N.D. Chasteen, Struct. Bonding 53 (1983) 105-138.

[2] D.C. Crans, Comments Inorg. Chem. 16 (1994) 35-76.

[3] P.J. Stankiewicz, A.S. Tracey, D.C. Crans, in: H. Sigel, A. Sigel (Eds.), Metal ions in Biological Systems: Vanadium and its Role in Life, Marcel Dekker, New York, 1995, pp. 287-324.

[4] R.W. Lymn, E.W. Taylor, Biochemistry 10 (1971) 4617-4624.

[5] Y.E. Goldman, Ann. Rev. Physiol. 49 (1987) 637-654.

[6] C.C. Goodno, Proc. Natl. Acad. Sci. USA 76 (1979) 2620-2624.

[7] C.C. Goodno, Methods Enzymol. 85 (1982) 116-123.

[8] S.J. Smith, E. Eisenberg, Eur. J. Biochem. 193 (1990) 69-73.

[9] R.G. Yount, D. Lawson, I. Rayment, Biophys. J. 68 (1995) 44s49s.

[10] T. Tiago, M. Aureliano, C. Gutiérrez-Merino, Biochemistry 43 (2004) 5551-5561.

[11] T. Hiratsuka, J. Biol. Chem. 268 (1993) 24742-24750.

[12] C.R. Cremo, G.T. Long, J.C. Grammer, Biochemistry 29 (1990) 7982-7990.

[13] E.M.V. Pires, S.V. Perry, M.A.W. Thomas, FEBS Lett. 41 (1974) 292-296.

[14] S.S. Margossian, S. Lowey, Methods Enzymol. 85 (1982) 55-72.

[15] J.D. Pardee, J.A. Spudich, Methods Enzymol. 85 (1982) 164-181.

[16] M.M. Werber, M. Peyser, A. Muhlrad, Biochemistry 31 (1992) 7190-7197. 
[17] M. Aureliano, V.M.C. Madeira, Biochim. Biophys. Acta 1221 (1994) 259-271.

[18] I.R. Gibbons, G. Mocz, Methods Enzymol. 196 (1991) 428-442.

[19] C.R. Cremo, G.T. Long, J.C. Grammer, Biochemistry 29 (1990) 7982-7990.

[20] J.J. Correia, L.D. Lipscomb, J.C. Dabrowiak, N. Isern, J. Zubieta, Arch. Biochem. Biophys. 309 (1994) 94-104.

[21] S. Hua, G. Inesi, C. Toyoshima, J. Biol. Chem. 275 (2000) 3054630550 .

[22] Y.M. Peyser, M. Ben-Hur, M.M. Werber, A. Muhlrad, Biochemistry 35 (1996) 4409-4416.

[23] R. Smith, I. Rayment, Biochemistry 35 (1996) 5404-5417.

[24] I. Ringel, Y.M. Peyser, A. Muhlrad, Biochemistry 29 (1990) 9091-9096.
[25] C.R. Cremo, J.C. Grammer, R.G. Yount, J. Biol. Chem. 264 (1989) 6608-6611.

[26] J.C. Grammer, R.G. Yount, Biophys. J. 59 (1991) $226 a$.

[27] P. Chaussepied, M.F. Morales, R. Kassab, Biochemistry 27 (1988) 1778-1785.

[28] J.C. Grammer, J.A. Loo, C.G. Edmonds, C.R. Cremo, R.G. Yount, Biochemistry 35 (1996) 15582-15592.

[29] A.V.S. Rao, T. Ramasarma, Biochim. Biophys. Acta 1474 (2000) 321-330.

[30] M. Aureliano, V.M.C. Madeira, Adv. Environ. Sci. 30 (1998) 333-357.

[31] D.C. Crans, Comments Inorg. Chem. 16 (1994) 1-33.

[32] T. Tiago, M. Aureliano, R.O. Duarte, J.J.G. Moura, Inorg. Chimica Acta 339 (2002) 317-321. 